\title{
LEGAL MEDIA DISCOURSE AS A MODERN PHENOMENON OF DISCURSIVE AREA
}

\author{
Gulchehra Noruzova \\ Kazakh Ablai Khan University of International Relations and World Languages, KAZAKHSTAN, \\ gulya bakrimovna@mail.ru
}

\begin{abstract}
The article focuses on the legal media discourse as a contemporary and complex communicative phenomenon, which is at the interface of two major and widespread institutional types of discourses - the legal and the media discourses. Having closely intertwined with each other, the legal and the media discourses form a special type of discourse known as the legal media discourse which is realized in the field of mass communication and aimed at integrating mediated legal topics and categories in a daily reality. Moreover, the author also considers the position of legal media discourse in the discursive area.

The author proposes the hypothesis that the legal media discourse is a kind of media discourse and increasingly- institutional discourse that has specific features related to its mass informational nature. This hypothesis is based on the arguments and conclusions of the scientists studying the legal discourse as a meaning-reproducing activities aimed at regulating and supervising the public relations through a system of social control, which is created with the help of such institutions as education, religion and the media; and considering the media discourse as any kind of discourse, realized in the field of mass communication produced by the media. Author argues that the legal media discourse is seen as a special kind of media discourse, as a result of mediatization of the legal discourse, which is characterized as a process of broadcasting and interpretation of mass information of the social and legal nature by the mass media. In this case, the media are an important tool not only in the interpreting and popularizing of the legal concepts and reality to a wide audience, but also in the improving of legal literacy and legal culture. Thus, having many similarities, the author concludes that the media discourse and legal discourse intersect in some area of its application.
\end{abstract}

Keywords: discourse, legal discourse, media, legal media discourse, mediatization.

\section{INTRODUCTION}

Today's domestic and foreign science has no widely accepted definition of «discourse» covering all the aspects of its use. This constitutes the complexity of this multi-dimensional phenomenon and contributes to the widespread popularity acquired by this term during the last decades.

In the words of James Paul Gee, a specialist in the field of sociolinguistics and discourse analysis, "for each of us the whole life - is not nothing but a patchwork of thoughts, words, objects, events, actions and interactions in the discourse" (Gee, 1990). Different approaches to the definition of discourse have already been presented in many research works of such scholars as Makarov M.L., Karasik V.I., Kozhemyakin E.A. 
and etc. However, the continued scientific debate over the past decades towards the content of this concept makes it so relevant nowadays.

According to Teun A.van Dijk discourse «gives a clearer picture of the things or people, their properties and relations, events or actions or their complex interaction that can be defined as some of the fragments of the world, which we call a social situation". Therefore, the model is a cognitive correlate of this situation: this is that "what's on a man's mind", when he is an observer or a participant in a situation when he hears or reads about it» (van Dijk, 1989, p. 137). As evidenced by the above definition, not only the statement is scientist's central proposition, the cognitive and situational settings that affect the form and content of this statement are also taken into account.

\subsection{Contemporary Understanding of Discourse}

In modern linguistics, discourse is often understood from the standpoint of the activity approach. This discourse structure is seen as the unity of the text and the context, the linguistic and socio-cultural components. The interpretation of discourse given by Krasnyx V.V. is particularly typical in this regard. He considers that «discourse as a verbalized speech and thought activity is understood as a set of process and outcome and having proper linguistic and extralinguistic plans» (Krasnyx, 2001, p. 270). It seems that the outcome refers to the verbalized result of this activity. This is a collection of texts generated in the communication process and is essentially the actualization of this discourse. In analyzing the discourse as a process, discourse is the verbalized («here» and «now») speech and thought activity, immediate understanding of the information received by the interpreter. From this definition, V.V. Krasnyx believes that the discourse has two plans - the linguistic and linguistic - cognitive. The first relates to a language, manifests itself in the use of language means and is manifested in the aggregate generated texts (discourse as a result). The second is associated with linguistic consciousness. It determines the choice of language means, affects the generation and perception of texts appearing in the context of presuppositions (discourse as a process). Moreover, the scientist doesn't only draw attention to the specifics of discourse understanding as speech and thought activity including the process and its result at the same time, but also to the extralinguistic factors characterizing the communication situation.

Arutyunova N.D. takes a similar view on the abovementioned discourse understanding and considers discourse as «a coherent text together with the extralinguistic, pragmatic, sociocultural, psychological and other factors» as «a speech immersed in life in time-setting mode» (Arutyunova, 1990, p. 137). This means that as discourse appears and develops all the social, cultural and pragmatic factors must be taken into account in analyzing the discourse. Therefore, unlike the text, the term discourse does not apply to the ancient texts and other texts that cannot be restored directly from real life.

Kubryakova E.S. and Alexandrova O.V. in their studies define discourse primarily as a cognitive process associated with speech production and speech work creation while the text is seen as the result of the speech process activity, which have a certain completed and recorded form (Kubryakova, 1999)

Understanding the discourse through the prism of cognitive (mental) activity combines linguistic, social and psychological aspects of the research subject. The study of the generating processes in understanding the text together with the psychological and socio-linguistic aspects involves the study of person's speech behavior in the context of his social space.

Many researchers specify linguopragmatic nature of discourse associated with the generation of the signs expressed in the form of speech utterances, texts, visual, indexical and other semiotic units. So, concretizing the linguopragmatic aspect of discourse, T.M. Grushevskaya adds: "Discourse is the cognitive process associated with the actual speech production and speech work creation that is the text that appears as a result of speech activity poured into a certain completed and recorded form» (Grushevskaya, 2002, p.166). It should be noted a procedural nature of discourse presented in this definition and its formalized expression in the form of text.

Emphasizing the communicative nature of the phenomenon, its sensitivity to a particular social situation, the concept of discourse includes psychological, social and cultural factors that are essential for its production and understanding. On the one hand, discourse addresses the situation in which different socio-cultural context defines the rules of conversation, adequate forms of expression and the goal towards which it is directed. On the other hand, discourse addresses the man. Communicants interact, provide feedback, and implement power. The discourse reflects ideas about the people speaking about the world, their opinions, 
relationships, attitudes and intentions.

According to E.F. Kirov, discourse is a combination of written and oral texts in a particular language within a particular culture throughout their history (Kirov, 2004). It is obvious that the position of E.F. Kirov is close to the conclusions made by N.D. Arutyunova in the sense that discourse is a set of written or oral texts and the situation of their creation and updating. However, in this approach discourse to a certain extent is predicated on specific national and cultural conditions, which means that the discourse content depends on the general cultural context through which it is implemented.

Thus, many authors assume that discourse is understood as the "verbalization of certain mentality" (Mikhaleva, 2004), which includes not only the reflection and interpretation of reality, but also the construction of an orderly world inherent in specific society. Since the discourse as "the text in event-aspect" invariably reflects the peculiarities of the national language, national culture and language consciousness. In addition, each discourse creates a distinctive view of the world, simulates a "mental world", which is a dynamic and streamlined body of knowledge about the covered discursive thought of reality. It also models its algorithm of meanings articulation and methods of objectification, a set of discursive formulas - words, phrases, locutions, cliche, that is "the peculiar turns of speech peculiar to communication in an appropriate social institution" (Karasik, 2004, p. 290).

Based on the above, the appropriate approach would be to consider that discourse is determined by three aspects: a) the language use; b) the cognitive - the transmission and construction of ideas and beliefs; c) social and pragmatic, when communicants interaction in specific socio-cultural contexts (Pihtovnikova, 2013).

Some linguists distinguish dialogic nature of discourse. In this case, discourse is understood as an interactive, dialogical way of speech interaction. An essential characteristic of communication - dialogue between participants of communicative interaction is the presence of feedback in the form of aggregate serial orderly exchange of communicative acts (speeches). Moreover, this interactivity aims to exchange views in order to achieve public consent or disagreement. An appeal to public opinion reveals the involvement of discourse to a system of political and social institutions.

Discourse, as well as any communication act presupposes the existence of two fundamental roles: the speaker (author) and the listener (an addressee). If the role of the speaker and addressee in turn is redistributed between discourse participants, so such discourse is called as dialogue. If during the discourse role of the speaker is performed by the same person, so such discourse is called monologue. Although the monologue and dialogue are always sharply contrasted with each other, but the monologue is the dialogue in a special case because it also requires addressee (Gurochkina, 1999).

There are many classifications of discourse, although any one of them to a large extent is contingent. The most important distinction in this area is the opposition of oral and written discourse. This distinction is related to information transmission channel: channel in oral discourse is acoustic while in the written discourse is visual. Oral discourse is the original, fundamental form of practical existence of language whereas the written discourse is derived from the oral, because the majority of human languages to this day are non-written, they exist only in oral form (Ahtaeva, 2010). In this case, the difference in the information transmission channel has fundamentally important implications for the processes of oral and written discourse. In oral discourse the generation and understanding is fully synchronized. The written form of language was originated as a way to overcome the distance as the spatial and temporal between the speaker and the addressee. A special range of methodological issues are associated with transcribing of oral discourse.

Any attempt to objectively written fixation (transcription) of oral language forces to solve many complex interpretational and technical problems. While fixing the speech not only the words are important, but also a variety of other circumstances as pause, prosody, laugh, the imposition of the replica, replica incompleteness and etc. Without these details meaningful analysis of oral discourse is simply impossible (Prokoshenkova, 2006, p.4).

More specific differences between the varieties of discourse described using the concept of genre. Genres are generated to provide the design and expression of a certain discourse. Each type of discourse is implemented in conjunction with certain genres that is typical models of cognitive and communicative practices that involve "the actualization of all the processes associated with producing, organization, 
processing, storage, transformation and messaging" (Alefirenko, 2007).

In the study of functionally-conditioned discourse in general, it should be noted that the concept of discourse is traditionally distinguished from the concept of «text». This is due to the fact that the discourse is primarily associated with oral speech and defined as «speech immersed in life", while the concept of text implies a connection with the written language. Whereas previously the discourse in many studies was used almost synonymously with the term text, in further these concepts were differentiated. Since discourse is namely characterized by spontaneity in a specific communicative situation taking into account verbal and nonverbal means and by personal contact between communicants, generation and perception of speech in a unity of time and space. While the text is characterized by the combined semantic relations, the sequence of sign units, the basic properties of which are connectedness and integrity, that is, deliberate, mediated and processed speech. Moreover, the text has certain lexical, grammatical and tectonic means that are unique to the text and cannot be applied and passed through discourse.

Currently the discourse and text relate to each other as the process and product of speech communication as a dynamic and static. Thus, the discourse is interpreted as an interactive, dialogical method of speech interaction, and the text is primarily interpreted as monologue_speech. There are other criteria of their differentiation. M.L. Makarov said that «in many functionally-oriented researches there is a tendency to pit the discourse and text by a number of opposite criteria: functionality - structural properties, process - product, dynamic - static and topicality - virtuality. Accordingly, the structural text and functional discourse are obviously different, since the text is understood as a product and the discourse as a process» (Makarov, 2003, p. 87).

E.I. Sheigal identifies the following versions of these categories in the ratio of linguistic studies:

1. the text is viewed as «a verbal recording" and the discourse - as a speech immersed in life, as a language of living communication;

2. the discourse is presented as the activity and procedural phenomenon associated with speech production, and the text is presented as a finished product, the result of speech production having completed form;

3. discourse and text are associated by the implementation ratio: discourse is reflected in the text; discourse is treated as a speech event in the course of which the text is created as a mental construct;

4. discourse is associated only with oral speech while the text - with its written form;

5. the term «discourse» serves a generic term in relation to the specific concept «speech» and «text»; discourse integrates all the parameters inherent to speech and text (speech is connected with the sounding substance, which is spontaneous and not normative; text is different as it uses graphic representation of language material, the text is prepared and considered standard);

6. discourse is treated as a communicative event aimed at interacting of communication actors through verbal texts and other symbolic systems in certain contexts of communication; This approach can be represented by the following formula: "discourse $=$ text + interactivity + situational context + cultural context» (Sheigal, 2004).

Some researchers believe that the relationship between discourse and text are indirect. Thus, according to an Australian specialist in the field of discourse - analysis Gunther Kress, the discourse has a social background but the text - linguistic. Discourse is a way of speaking due to social institutions and social relations. This social base is emphasized in such terms as "legal discourse», "medical discourse», "racist discourse". Features of discourse are expressed in linguistic form. In turn, linguistic form presented in the text represents specific aspects of discourse. Gunther Kress says that any single text can be the result of many discourses, which are often contradictory. Since the text is rarely intact in terms of linguistic features that it contains, or discourses, which it expresses (Kress, 1985, p. 28-29)

In general, the concept of discourse interpreted by different scholars in various ways, the occurrence of which is associated with the release of linguistic research in the area of super-phrasal syntax. It is namely an integrated unit consisting of a series of proposals combined by logical and semantic type of connectivity. In other words, the discourse is a linguistic unit of higher level, which has structural and functional characteristics. This is «new feature in the language form as it appeared before us at the end of the XX century» (Stepanov, 1996, p. 71). The main property of discourse is its lack of clearly defined borders that is 
a consequence of its processuality and intertextuality, as well as the result of constant transformative human activity (Dubrovskaya, 2010, p.10).

Thus, society spontaneously and deliberately organize and generate in their communicative space certain discourses - as a socially regulated intellectual and pragmatic (cognitive-suggestive) formation sphere (Polonsky, 2011, p.176); - as a socially ordered, regulated practice (process and result) of objectification in the aggregate of characteristic, genre specified texts of a certain type of consciousness. This reflects the special logic of knowledge about selected fragment of reality and the ways of speaking about it. The discourse is defined as the postponed and entrenched ways of seeing and experiencing the world, ways of streamlining of social reality in the sign system.

The main approaches to understanding the discourse have been analyzed. Based on the reviews, some of the characteristics and peculiarities of the studied scientific category has been identified. Thus, many researchers have noted the dynamic nature of the discourse as the activity and procedural phenomenon attached to time and implemented both in written or oral form. In addition, some linguists understand discourse as a complex social and communicative phenomenon, which, besides cognitive and pragmatic factors, includes the extralinguistic components such as psychological, social, cultural factors which are necessary for an explanation for this phenomenon.

If earlier in many studies discourse and text were almost synonymous terms, now the discourse and text are differentiated and relate to each other as the process and product of speech communication as a dynamic and static.

Finally, it should be noted that the discourse, by its nature, can be both process (exchange of communicative acts) and the result of this process (the set of visual or verbal units of semiotic nature)

Based on the selected characteristics of the studied scientific category, it should be marked that in this study we understand a discourse as a communicative speech activity, during which the socio-role, socio-cultural, psychological, cognitive and communicative aspects are clamped.

\subsection{Institutional Characteristics of Legal Discourse}

As previous review has shown, according to many researchers, the discourse creates a certain social reality, in which the participants have different social roles and communicative settings that affect the flow of discursive activity. In this context, there are two types of discourse - the personal (person-oriented) and institutional (status-oriented). Institutional discourse is a dialogue within the given bounds of status-role relationships allocated on the basis of two criteria: the purpose and participants of communication (Karasik, 2000).

According to E.G. Malysheva, institutional discourses are understood as complex discursive spaces organized on the principle of field of the discursive variety system united primarily by common themes and conceptual dominants that are represented within the discourse (Malysheva, 2011).

Thus, the concept of institutional discourse proposed by E.I. Sheigal covers both language system and speech activity and text. According to this interpretation, discourse appears as a formula discourse = sublanguage + text + context. Such terms as political discourse and political communication are used interchangeably by the author (Sheigal, 2004).

Institutional discourse is a very broad concept covering both the language system (such part of language system that is specifically oriented to the handling of the given communication area) and speech activity (a set of linguistic and extra-linguistic factors) and text. Moreover, the institutional discourse is based on a certain system of professionally-oriented signs, in other words, has its own specific sublanguage (special vocabulary, phraseology).

In this regard, it should be noted, that different researchers distinguish different types of institutional discourse, such as the political, legal, military, educational, religious, medical, business, advertising, sport and etc. In short, the institutional discourse occurs in such environments where the functions of any social institution are implemented.

The study identifies the characteristics of legal discourse as a kind of institutional discourse on the basis of 
characteristics of the participants in the communicative situation. Based on the provisions of the discourse system in general, it can be assumed that the legal type of discourse is an integral element of the overall system that has its own constitutive, systemically important features that distinguish it from other types of discourse.

Legal discourse has a special place in the general system of discourse types. Legal discourse is recognized as institutional discourse, as it has its own categorical features that distinguish it from the common system. We support L.V. Slavgorodskoy's opinion that these constitutive features include special purpose (specialized perspective), the characteristics of standard participants and form of existence of discourse relations.

Of the many varieties of institutional discourse, legal discourse is a status-oriented interaction between its participants in accordance with the system of role prescriptions and norms of behavior in certain situations, namely institutional communication (Maltsev, 2007, p. 412).

According to T. V. Dubrovskaya, legal discourse is a type of institutional communication, which is a complex, many-voiced formation with a large number of participants carrying out their roles and functions agreed by the institutional rules (Dubrovskaya, 2010, p.26).

In addition, legal discourse is a "semantic and reproducing activity regulated by certain historical and sociocultural codes (traditions) and aimed at formulating the norms, the legal consolidation (legitimacy), regulation and control of public relations through a sustainable system of legal norms" (Kozhemyakin, 2011, p.131). Legal communication, in addition to the formulation of legislation aimed at regulating social relations, is also characterized by the fact that this type of discourse is a space created on the one hand, for a small group of people having particular expertise (legal specialist), and on the other hand - for a group of individuals interested in obtaining this knowledge, but are unable to perceive them due to the complexity of the discourse information (Pervukhina, 2013, p.136-137).

Language of legal discourse is unique, as it represents one of the most peculiar communicative codes which are traditionally used in the institutional environment. Its uniqueness is reflected in the wide use of conceptual-semantic language means (terms), cliches and officialeses, the deliberate attempt to take out the expressive means, the complexity of syntactic structures, the sustainable use of limited spectrum of genre and stylistic means, the low contextuality (Kozhemyakin, 2011, p.133).

Meanwhile, it should be taken into consideration that impressive terminological richness of legal texts poses certain difficulties in their understanding and creates the need for their interpretation, not only for the "naive" recipient, but also for a professional lawyer. It is also worth mentioning that in addition to the units set forth in the legislation, legal terms also include lexical units fixed in the specialized and general press. Certainly, the language of legal discourse tends to clarity and unambiguous wording. Therefore, unprepared recipient often has stylistic, terminological and cognitive obstacles to its understanding. So, addressee needs assistance in that regard for the perception and interpretation of the legal discourse. Such assistance may be provided to the recipient, not just through consultations with the legal specialists, but also using the media.

Thus, according to the above definitions, the legal discourse is characterized by a communicative nature, thematic certainty, the presence of a specific aim, namely the control of social reality. "Having the political, socio-cultural and economic reasons to realize the goal, legal discourse is also based on a system of social control which is created by other institutions, such as education or religion" (Kozhemyakin, 2011, p. 132). It seems that one of these institutions is the media which can play a significant role in the process of meaningmaking as well as in the system of social control (Silanova, 2014).

The most important feature of the legal discourse is that this type of institutional discourse unfolding in the media space operates in the inter-institutional and cross-cultural environment overlapping and interacting with other discourses. Some language dominants of legal discourse can send us to the values and principles of such cultural institutions as politics, religion, economics and others which are exclusively inherent to this type of discourse. "Legal actions are characteristic for almost all the cultural institutions and some legal category is firmly rooted in the subject areas of political, economic, religious, educational and other cultures (Kozhemyakin 2011, p. 132). Thus, discursive legal media space will include texts created at the junction of the legal discourse and the discourse of another type (scientific, journalistic, political, domestic, medical and even artistic).

Legal communication is not simply mediated, but the media has actually started playing a significant role in 
the interpretation of legal discourse. They are the active interpreters affecting the transmitted meaning and serving interest groups. It is important to point out that media discourse now plays a special role in the understanding of legal discourse. Since media discourse is the main channel for conducting intermediary activity in the modern era. In this connection, it is appropriate to speak about the trend towards merging of legal discourse with media discourse.

\subsection{Legal Media Discourse as a Modern Phenomenon of Media Space}

The media is one of the most important institutions of modern society. They perform multiple functions, for example, they inform and educate the general public, advertise and entertain. It is clear that they play an important role in the perception and interpretation of the most important phenomena and events of the social and legal nature that take place in the country as well as in the whole world.

The specific feature of the media as a social institution is to provide a full picture of social life through the media coverage of every social institution - that is the creation of an information analogue of society (Chernyh, 2008).

In other words, due to the global nature of communication in the modern world, its inclusiveness and multilevel data transmission system a discourse becomes of mass-informative (Aleschanova, 2000) or mass - media (Zheltuhina, 2003).

Media discourse is characterized by topicality, which, however, does not always correspond to the real value and importance of the event. In this sense, the media discourse "is a semiotic space that, due to the sign nature of language, is divided according to the general semiotic theory on the semantics, pragmatics and syntactics reflecting the interaction of semantic, compositional and motivational factors (Arutyunova, 1990).

Today, there are at least two main approaches to the definition of media discourse. According to the first, media discourse is a specific type of speech and thought activity particular to the information media space. In this sense a distinction should therefore be made between media discourse and other independent types of discourse, such as political, legal, religious, scientific and etc. The differences between them are determined by modifications of various discourse parameters such as a variety of language practice, various communicative situations of their implementation. Although these discourse speech may address an overall thematic field. In particular, according to this view, the media discourse is characterized by the presence of specific systemically important concepts - "good" and "fact" (Polonsky, 2009). Under the second approach, the media discourse is conceived as any kind of discourse and realized in the mass communication space. So, we can talk about the political, religious, educational, legal and other media discourse, implying that for their implementation these types of institutional discourse involve a relatively stable set of production practices, translation and interpretation of the media.

In our study, we take the second point of view and define the media discourse as a thematically focused, socio-culturally - conditioned speech and thought activity in the mass media space. A fundamental difference of this type of discourse is that in addition to the production of certain knowledge, objects and images assessment as a result of speech and thought activity, it also creates an understanding of the ways of knowledge transmission. In this regard, the media discourse is highly mediation activity. In the media discourse there is conversion of information into meanings (the knowledge construction), the knowledge transfer from one level (e.g., institutional) to another (e.g., ordinary), fusion of different types of information (for example, political and legal, event-oriented and advertising) or creating of special knowledge pertaining only to the media reality (Kozhemyakin, 2010, p. 16). In other words, the central subject of media discourse is not so much political processes, but many ways to describe and transfer of knowledge about them. Thus, while examining the legal media discourse, a central subject of this media discourse is not so much the lawmaking or law enforcement processes, but many ways to describe the results of law-making processes including, for example, legal judgments about the rightness or wrongness of particular actions and the knowledge transfer about them.

Given the similarities between legal and media discourse, these discourses intersect in some area of their application. For example, the text of the law refers to the legislative discourse as a subtype of the legal discourse, but the news line about its enactment or different interpretation and explanation of its application in the author's column will be treated as a legal media discourse (Silanova, 2014). 
Legal media discourse is primarily defined as a special type of media discourse involving the existence of translation and interpretation of the mass information of social and legal nature which produced by channels of mass communication. The specialized information and communication channels that technically and technologically provides a process of mass communication ensure the immediate distribution and delivery of socially important information addressed to a wide audience. Such channels include press (periodicals), radio broadcasting, TV channel, Internet (specific information environment providing access to their resources and formed by an electronic memory located on different computers linked with each other by specific protocols). In metaphorical expression of Y.N. Zasursky, Internet now resembles a "street without traffic rules" that must be installed "to provide access to reliable sources, to find sites that can be treated with confidence» (Zassoursky, 2008).

With the growing mediatization process (the process of mass media influence on events of social and legal nature) the role of the media in the interpretation of legal concepts and judgments is becoming increasingly important, because the media serve as a vehicle, a means or a combination of tools that provide storage, representation and transfer of information resource incorporated into one or another semantic-symbolic form (code).

As A.V. Sokolov rightly noted that the "Media as a technical-technological phenomenon and specified sign environment act as information and communication channel, through which information becomes available to the particular addressee. The communication channel is the "real or imagined communication line (contact) by which messages move from the communicant to the recipient. The communication channel provides the communicant and recipient with the tools for creating and perception of messages that are signs, languages, codes, physical media reports, technical devices. Communication channels don't provide movement of meanings, but provide only the materialization of messages that express the semantic content (Sokolov, 2002). Due to the fact that legal information is available only to a certain group of people (lawyers and citizens at the time when the criminal or civil offence was committed) and significant only in cases of any relationship and effects of legal nature, then, in this case, the mass media, along with other social institutions are an important means of contributing to the popularization of legal information for a wide audience. Thus, the media act as a mediator not only between social actors ensuring their interaction, but also between social reality and the public, every time revealing its subjective, that is ideological, value - oriented attitude.

The most important task of the media as a social institution is to meet the needs of society in a regularsystematic development of the current social context, photography of actual social reality, rationalized extraction, processing and transmission of information to the general dispersed audience providing mass, orderly, regular, periodical distribution of social important information (Vartanova, 2003). In our case, one of the main objectives of the legal media discourse is a regular periodic distribution and integration of legal realities and categories in the everyday reality with the aim of informing the general public about the most significant law-oriented judgments. They include: commentaries on legal acts, legal answers to readers' questions, materials on judicial topics, publications about the work of law enforcement bodies, prosecutors and police.

The process of interpretation of legal texts in order to clarify their meaning to the audience of mass communication, who are individuals or social groups, is the most important component of the mediatization of legal discourse. Passing through the different levels of interpretation, legal discourse enters into the public space and is subject to the process of mediatization. However, mediatization cannot be perceived as a unilateral process of transferring legal discourse on the language of the mass audience. Mediatization of legal discourse involves complex processes, which can be divided into several stages: the interpretation of the legislative text, then the spread of this interpretation to a wide audience through the media, formation of public opinion, which, as a system of social control brings us back to the stage of regulation of social reality (Silanova, 2014). In general, such a set of stage-by-stage actions reveals the interpretation features of the legislative discourse as the main subtype of legal discourse characterized by strong pragmatic orientation to the addressee. The text of the law is created due to the current events, facts and circumstances in different social environments that need legal influence and control. Thus, existing due to the subjective factors, it interacts with other discursive complexes and functions in different social spheres. The main purpose in the course of mediatization of legislative discourse is not only the disclosure of the true meaning and content of the law and its regulations, as well as the formation of public opinion in the light of the positive and negative attitudes towards the law for the purpose of its further amendments.

According to E.N. Tonkov, it is important to understand that «the law alone cannot operate; the actors are people who perceive legal regulations through their individual legal conciseness» (Tonkov, 2013, p. 232). 
Trying to understand the meaning of a rule, reader always skips written statement through the prism of their individual experiences, context. Accordingly, the legislator's intent is perceived differently, which means that the degree of its acceptance and application will depend on the individual characteristics of the interpreter, and will come out of his will, feelings, temperament, thinking, character and abilities. Thus, in the "real world not the law itself has a great affect, but its certain interpretation» (Belkin, 1995, p. 32).

By informing legal media discourse promotes legal literacy, in which the media play a key role. As the media have the unique ability to generate intense information - semantic (cognitive) flows and strictly control them.

\section{CONCLUSION}

Thus, the legal media discourse occurs at the intersection of the legal discourse and media discourse. It is proposed to use the following working definition: legal media discourse is a complex communicative phenomenon, which has the aim to improve legal literacy including the text as a result of verbalized speech and situational, socio-cultural and pragmatic context, as well as special language means to meet the goals and objectives of this discourse.

In this article, we studied the origins of the legal media discourse. According to the hypothesis of the given study, the legal media discourse is defined as a special type of media discourse, which, in turn, is one of the types of institutional discourse. Overview of features of two types of institutional discourses overlapping in some area of their application, the study of their properties, functions, allowed us to define legal media discourse as a modern phenomenon of discursive area.

\section{REFERENCE LIST}

Arutyunova, N.D. (1990). Discourse. Linguistic encyclopedic dictionary. Soviet Encyclopedia Publ.

Ahtaeva, L.A. (2010). Scientific discourse as a specific kind of discursive activity. Young scientist. - 2010.№7

Alefirenko, N.F. (2007). Speech genre, discourse, culture. Type of speech: Coll. scientific articles. - Vol. 5. The Genre and Culture. "Science» Publishing Center.

Aleschanova, I.V. (2000). Newspaper text as a kind of mass-information discourse. Linguistic personality: institutional and personal discourse: Collec. Scientific articles: Issue 1/ Volgograd State Pedagogical University.

Belkin, A.A. (1995). Constitutional protection: three aspects of Russian ideology and practice. "Petropolis" Publishing Center.

Chernyh, A.I. (2008). Sociology of Mass Communications. Textbook. Publishing House of High School of Economics.

Dijk, van T.A. (1986). Language. Cognition. Communication. "Progress" Publishing House.

Dubrovskaya, T. V. (2010). Judicial discourse: judge's speech behavior: Dissertation abstract of Dr. Philology. Science. 10.02.19.

Gee, James Paul. (1990). Social linguistics and literacies: Ideology in discourses. Critical perspectives on literacy and education. Falmer Press.

Grushevskaya, T.M. (2002). Political discourse in the aspect of a newspaper text. RGPU publishing house of A.I. Herzen.

Gurochkina, A. G. (1999). The concept of discourse in modern linguistics [Text]. Nomination and Discourse: Inter-University collection of scientific papers.

Krasnyh, V.V. (2010). Fundamentals of psycholinguistics and communication theory: Lectures. ITDGK "Gnosis".

Kubryakova, E.S. (1999). On the contours of a new paradigm of knowledge in linguistics / Kubryakova E.S., Alexandrova O.V. // Structure and semantics of a literary text. Reports of the VII Intern. Conf.

Kirov, E.F. (2004). The chain of events - the discourse / text - concept // Actual problems of linguistics and intercultural communication. Lingua-didactic aspects of intercultural communication: materials of scientific session of the Faculty of LiMK Volgograd State University. Collection of scientific articles. 
"Volgograd" publishing house, Vol. 2.

Kress, G. (1985). Ideological Structures in Discourse // Handbook of Discourse Analysis. Vol. 4. Discourse Analysis in Society.

Karasik, V.I. (2004). Linguistic circle: personality, concepts, discourse. monographia. Second edition. «Volgograd» publishing house.

Karasik, V.I. (2000) Types of discourse // Linguistic personality: institutional and personal discourse. Peremena.

Kozhemyakin, E.A. (2011). Legal discourse as a cultural phenomenon: the structure and smysloobrazovanie. Legal linguistics -11: Law as a discourse, text and word: Inter-university collection of scientific papers / edit. by Goleva N.D. and Brineva K.I.; Kemerovo State University.

Kozhemyakin, E.A. (2010). Mass communication and media discourse: to research methodology. Scientific statements of Belgorod State University. Series: Humanities.№12 (83).

Mikhaleva, O.V. (2004). Political discourse as the scope of the implementation of the manipulative influence. Dissertation abstract of Cand. Philology. Science. 10.02.01.

Makarov, M.L. (2003). Fundamentals of discourse theory._Gnosis.

Malysheva, E.G. (2011). Russian sport discourse: theory and methodology of the linguacognitive studies. Dissertation abstract of Cand. Sciences. 10.02.01.

Maltsev, G.V. (2007). Social foundation of law. Monograph.

Pihtovnikova, L.S. (2013). Discourse in the aspect of informativeness. URL: http: // synergy. kh. ua / discurs2.html

Prokoshenkova, L.P., Getskina I.B. (2006). Discourse analysis and its role in modern linguistics. Vestnik of Chuvash University № 4.

Polonsky, A. V. (2011). Discourse: root phenomenon of culture and social communications. Language of professional communication and linguistic studies: Collection of papers in intern. scientific practical seminar / ed. By Samosenkova T.V. IPK NIU "BelSU".

Pervukhina, E.V. (2013). Semantic and syntactic characteristics of the adapted text in the legal discourse. Philological science. Theory and practice, № 4 (22) 2013, Part 2.

Polonsky, A. V. (2009). Modern media discourse: the key ideas and words. Russian language in the modern media space. Materials of Intern. scientific-practical. Conf. Belgorod State University.

Sheigal, E.I. (2004). Semiotics of political discourse. Diss. doctor.phil.sciences. Gnosis.

Stepanov, Y.S. (1996). Alternative world, Discourse, Fact and Principle of causality. Language and the Science of the late 20th century. Russian Academy of Sciences.

Silanova, M.A. (2014). Mediatization of legal discourse. Electronic scientific "Mediaskop" magazine Issue №4.. http://www.mediascope.ru/?q=node/1643.

Sokolov, A.V. (2002). The general theory of social communication // Publishing house of Mikhailov V.A., http://sbiblio.com/biblio/archive/sokolov_social_communication.

Tonkov, E.N. (2013). The interpretation of the law in England. Monograph.

Vartanova, E.L. (2003). Media economy of foreign countries. Aspekt Press http://www.gumer.info/bibliotek_Buks/Gurn/Vart/05.php\#sthash.CS2ZpIFS.dpuf

Zheltuhina, M.R. (2003). Tropological suggestiveness of mass media discourse: On the problem of speech influence of tropes in the language of the media. Monograph. Univ. VF IASC.

Zassoursky, Y.N. (2008). International Journalism in a multipolar world. Vestnic of electronic and print media. - Issue № 8. - Part 2. http://www.ipk.ru/index.php-id=160. 